\title{
Friendliness in Russian linguistic worldview
}

\author{
Tatyana Ryzhkova* \\ Irkutsk National Research Technical University, Institute of Linguistics and Intercultural Communication, 664074, Irkutsk, Russia
}

\begin{abstract}
This paper is regarded in the framework of anthropological linguistics and is devoted to the study of the notion of friendliness. Friendliness is defined as friendly disposition or friendly attitude of a person in relation to other people. The paper emphasizes valuable dominants of a friendly attitude kindness, benevolence, disposition and sympathy. The results of free association experiment allowed the author to generalize ideas about the notion of friendliness among native speakers and describe the image of a friendly person in the Russian linguistic worldview. Friendliness can be manifested by verbal and nonverbal means of communication that reflect positive and good-minded communication style. The paper discusses vocal expressions, lexical means of language, facial expressions, gestures, actions that are regarded as manifestations of friendliness. It is worth noting that the addressee experiences a wide range of positive emotions dealing with manifestations of friendly attitude. The research emphasizes that friendliness is highly valued in the Russian-speaking culture. The results of this paper contribute to the study of the linguistic image of a friendly person as a fragment of the Russian linguistic worldview.
\end{abstract}

\section{Introduction}

Linguistic studies of the late $20^{\text {th }}$ - early $21^{\text {st }}$ century are characterized by the involvement of the human factor in the research paradigm. The works of linguists discuss emotional and sensual processes of perception of the world by a person, ethical principles of human existence [1-7]. According to the ideas of existential philosophy that the essence of human being is reflected in the language [8], the description of linguistic and nonlinguistic image of a person is of current interest in the framework of anthropological linguistics.

This paper is regarded in the framework of anthropological linguistics and is devoted to the study of the notion of friendliness as a component of the inner person's world which is characterized by diverse mental states, experiences, desires, feelings, emotions, actions, reactions, perceptions. The different values of being, ethical principles of coexistence with the outside world are always connected with the sensual and emotional aspects of a person. The analysis of the notion of friendliness according to the data of dictionaries, free association experiment and literary works makes a certain contribution to the study of the linguistic image of a friendly person as a fragment of the Russian linguistic worldview.

The aim of this article is to study the notion of friendliness and its image in the Russian linguistic worldview. The tasks include solving the following problems: to study the notion of friendliness in accordance with the data of dictionaries; to carry out free association experiment to determine the lexical verbalizers of this notion; to determine the behavioral features of verbal and nonverbal manifestations of

\footnotetext{
Corresponding author: ryzhkova08@mail.ru
}

friendliness in the communicative space according to the data of literary works.

The material of the paper are data of dictionaries of the Russian language, data of free association experiment and text fragments of L.N. Tolstoy's novel "Anna Karenina" that contain descriptions of friendliness at the verbal and nonverbal levels which actualize actions and tactics of a friendly person in the process of communication.

In this research the following scientific methods are used: method of etymological analysis, method of analysis of dictionary definitions, method of component analysis of the lexical meaning of the word, the method of free association experiment. Etymological analysis of the word allows comparing the written history of the word and data of modern dictionaries to obtain more information about the semantics of the word. Method of analysis of dictionary definitions allows defining the word. The method of component analysis of the lexical meaning of the word involves the decomposition of the meaning of the lexeme into minimal semantic components and identification of its basic semantic features. The method of free association experiment lets to identify lexical verbalizers and generalize associations and ideas about the notion among native speakers. The analysis of the language material will emphasize linguistic and cultural features of the notion of friendliness in the Russian linguistic worldview.

\section{Results}

A certain way of perception and conceptualization of the world is reflected by a person in the linguistic worldview 
which has special features in linguistic and ethnic aspects and contains the historical and cultural experience of a certain nation. A person pictures with the help of the language "not only the world around him, but he pictures himself in this world" [3]. On the one hand, the linguistic worldview is a set of ideas about the world that is forming in the language throughout history. On the other hand, the linguistic view of a person begins to form since the preverbal period of human life. The results of information about the world are accumulating that leads to verbalization of cognition. Thus, the duality of the nature of the linguistic worldview is due not only to social and cultural experience of a nation, but also individual experience of a particular person and the peculiarities of his inner world.

According to A.A. Zaliznyak one of the key components of the Russian linguistic worldview is conceptualization of attitude of one person to another which includes internal, mental and external, conventional aspects [9]. The attitude of one person to another, "may manifest in some way, but may not be manifested without losing its existential status" [9].

Friendliness is actualized in consciousness of the Russian linguistic persona as "friendly attitude, friendly feeling, sympathy" [10], "friendly disposition, kind attitude" [11-13] of a person in relation to the outside world, to the people around him. A.D. Shmelev also points out that the adjective friendly and the adverb friendly describe first of all external manifestations of kindness but not mutual friendly feelings [9]. Indeed, a person can experience and show friendly feelings towards people around him who do not feel friendly feelings towards him, and accordingly do not show proper friendly disposition.

From viewpoint of etymology the word дружелюбие (friendliness) is relating to the words $\partial p y z$ (a friend) and любить (to love). Both words have strong positive semantics and connotation. According to the data of etymological dictionaries of the Russian language the word $\partial р y z$ (a friend) is derived from the Indo-European word *dhroughos that is derived from the verb *dhrugh-, in which the root of the word *dher- means 'to support', 'to prop up' [14]; 'to be ready', 'to be strong' [15]; 'to follow', 'to set out on the march', 'to fight' [16]. In the Old Slavic language the word $\partial р о у г ъ$ (a friend) has the following meanings - 'a friend', 'another', 'next' [15], in the Old Russian language другъ (a friend) means 'a friend', 'a comrade', 'a servant' [14].

Etymologically, the verb любить (to love) is relating to the Indo-European root *leubh-, then in the Common Slavic language is the verb *ljubiti (to love) present. There is the verb любити (to love) in the Old Slavic [14]. In the Old Russian language the dictionary already indicates the following meanings of the verb любить (to love) 'to love', 'to prefer', 'to admire', 'to kiss'. The noun любовь (a love) means 'love', 'affection', 'mercifulness' [14]. Thus, in the course of historical development of the word the following semes are distinguished: 'a support', 'a prop', 'attachment to a friend', 'love for a person'. These semes have formed basis of the semantics of the notion friendliness in the modern Russian language.
The etymological analysis of the word friendliness let us to determine that the word is formed by composition of two stems друж(е)- and люб-и-e, which have brought to the meaning of the word such semes as 'a support', 'a prop', 'attachment to a friend',' love for a person'. These semes are actualized in a friendly attitude or friendly disposition to surrounding persons.

In the modern Russian language friendliness is explained most accurately by the adjective friendly, cf.: "friendly attitude, friendly feeling, friendly disposition" [10-12]. The adjective friendly is not only directly related to the words friend and friendship, but it is interpreted as "imbued with affection, sympathy" or "good-minded" [12], "based on the mutual affection of people to each other" [11]. Thus, according to the definitions of explanatory dictionaries friendliness should be understood as kindly attitude or positive communication style based on disposition, friendly feeling and sympathy for the others.

In the dictionary of synonyms of the Russian language by Z.E Aleksandrova, friendliness is also explained by the word kindness. Benevolence is marked as synonym to friendliness. [17]. According to the analysis of the definitions in the dictionaries it is possible to emphasize valuable dominants of friendly attitude - kindness, benevolence, disposition and sympathy which are manifested in the friendly attitude of people to each other.

We have complemented the analysis of the dictionaries by data of free association experiment to obtain the most complete representation of this notion in the Russian linguistic consciousness. 80 respondents (35 male and 45 female informants aged 18 to 55) participated in the association experiment who are native speakers of the modern Russian language. The reactions on the word-stimulus friendliness vary considerably, but in the absolute majority they have clearly defined positive semantics. Friendliness is associated in the consciousness of most respondents with ideas about attitude towards another person in social environment: good attitude (22), then in a decreasing scale of reactions

- polite attitude (17), good-minded attitude (12), respectful attitude (7) and affable attitude (6). These reactions confirm the idea of A.A Zaliznyak that the concept of attitude belongs to the key components of the Russian linguistic worldview [9].

Friendliness is directly related to personal qualities such as kindness (30), sociability (22), openness (16), emotional generosity (11), sincerity (10), caring (5), conflict-free (4) and calmness (3). At the emotional level a sense of joy (10) and a feeling of warmth (7) dominate among the reactions. An important component by interpretation of friendliness is sympathy (16).

The answers of the respondents to the question "How do you understand that a person is friendly towards you?" allowed us to describe in detail the image of a friendly person in the Russian linguistic consciousness. A friendly person smiles (50), keeps up a conversation (22), shows interest (19), jokes (17), laughs (15). He is attentive (14), pleasant in communication (10), intends to be positive (10), takes delight in meeting (7). During a conversation it seems that you know a person for a long 
time (6). A friendly person does not say rude things. He is ready to help (52), supports (18). In the process of communication, a friendly person not only smiles, but also hugs (16), shakes hands (12), winks (8), claps on the shoulder (6). At the phonetic level, respondents mark a soft intonation (9), a friendly tone (7) and a friendly voice (7). A smile is often described as kind, sincere and affable.

Analysis of the data of the association experiment allowed us to emphasize the following dominants of a friendly attitude: kindness, sociability, politeness, openness, emotional generosity. At the nonverbal level a friendly person, as a rule, smiles, hugs, shakes hands, winks, claps on the shoulder in the Russian-speaking sociocultural environment. At the verbal level a friendly person uses tactics to keep up a conversation, shows signs of attention and shows interest in the affairs of the addressee, expresses his positive attitude, jokes, laughs. Friendliness is actualized through vocal expressions: soft intonation, friendly voice and friendly tone. The most significant manifestations of friendliness for the native speakers are assistance and support.

Thus, the data of the conducted free associative experiment emphasize that friendliness is highly valued in the Russian-speaking culture. A friendly attitude reflects a positively marked style of verbal and nonverbal behavior.

To illustrate aforesaid, let us consider the image of a friendly person in the Russian literature through the novel of L.N. Tolstoy "Anna Karenina". One of the main characters of the novel is Stepan Arkadyevich Oblonsky who is liked by people for his kind, bright disposition. $\mathrm{He}$ is respected in the office. His friends, acquaintances, relatives often seek his advice, for example:

Stepan Arkadyevitch was not merely liked by all who knew him for his good humor, but for his bright disposition, and his unquestionable honesty. In him, in his handsome, radiant figure, his sparkling eyes, black hair and eyebrows, and the white and red of his face, there was something which produced a physical effect of friendliness and good humor on the people who met him.

Let us analyze verbal and nonverbal means of manifestation of friendliness which Oblonsky uses in communication to be regarded as a friendly person by the people around him. At the verbal level a friendly attitude is manifested through the familiar and easy tone of Stepan Arkadyevich which allows him to communicate simply, freely, but at the same time formally with his subordinates in the office, for example:

A secretary, with the good-humored deference common to everyone in Stepan Arkadyevitch's office, came up with papers, and began to speak in the familiar and easy tone which had been introduced by Stepan Arkadyevitch [18].

A.A. Potebnya in his discussions on thought and language notes that "the word really exists only when it is pronounced" [19]. Indeed, any word can be pronounced in the tone of a friendly or hostile disposition, joy or grief, encouragement or reproach. The tone of the utterance allows the listener to evaluate the emotional state of the speaker, his relation to the addressee and to the meaning of the utterance.

Along with the familiar and easy tone of Stepan Arkadyevich, thanks to which a friendly atmosphere is created in his office, it should be noted his ability to communicate with all his acquaintances on familiar terms regardless of their age, position in society, the degree of acquaintance, for example:

Stepan Arkadyevitch was on familiar terms with almost all his acquaintances, and called almost all of them by their Christian names: old men of sixty, boys of twenty, actors, ministers, merchants, and adjutantgenerals, so that many of his intimate chums were to be found at the extreme ends of the social ladder... [18].

During communication with his acquaintances Oblonsky uses syntactic constructions in which elements of repeat are present. Thereby he strengthens the emotional component of the utterance, for example:

'I am very, very glad to see you,' he went on; 'Don't say, don't say a word!' [18].

The analysis of communicative behavior at the nonverbal level made it possible to emphasize the following facial expressions, gestures and actions which Stepan Arkadyevich uses by posing himself as a friendly person during a conversation. He looks at his partner in a friendly way, smiles, shakes hands, hugs, kisses, for example:

'Why, it's actually you, Levin, at last!' he said with a friendly mocking smile, scanning Levin as he approached. 'How is it you have deigned to look me up in this den?' said Stepan Arkadyevitch, and not content with shaking hands, he kissed his friend [18].

Communicative nonverbal behavior of Oblonsky is characterized by various touching that express sympathy, caring, support and assistance in difficult life situations, for example:

'You wait a bit, wait a bit,' said Stepan Arkadyevitch, smiling and touching his hand [18]. Touching Levin's hand, Oblonsky hastens to comfort his friend and express his support during the discussion of not very pleasant news.

'Oh, no, oh, no, not at all! Please understand me,' said Stepan Arkadyevitch, touching his hand again, as though feeling sure this physical contact would soften his brother-in-law [18]. This example emphasizes that in a communicative situation which takes place in a tense atmosphere and affects complex issues, Oblonsky uses a hand to calm down and soften his partner in conversation. Oblonsky succeeds in it thanks to his soft, noncategorical, friendly, communication style.

The effect of friendly touching is accompanied and amplified by a smile - a bright mimic movement. A smile is able to express a huge range of positive intentions towards the addressee - friendliness, benevolence, disposition, openness, sincerity, sympathy and, as a rule, positive emotions of joy and happiness $[20,21]$. L.N. Tolstoy characterizes the smile of Stepan Arkadyevich by the following adjectives - soft, kindly, almond, good-humored, for example:

'How do you mean for nothing?' said Stepan Arkadyevitch with a good-humored smile...; Again he (Oblonsky) smiled discreetly his almond-oil smile [18]. 
Oblonsky uses a smile to express that he understands feelings of the addressee, his pressing problems, for example:

Stepan Arkadyevitch smiled. He knew what was passing in Levin's soul [18].

Oblonsky is able to convince the addressee of the correctness of advice that he suggests to follow using his kindly and soft smile, for example:

'If you care to know my opinion,' said Stepan Arkadyevitch with the same smile of softening, almondoil tenderness with which he had been talking to Anna. His kindly smile was so winning that Alexey Alexandrovitch, feeling his own weakness and unconsciously swayed by it, was ready to believe what Stepan Arkadyevitch was saying [18].

Stepan Arkadyevitch manages to reduce the categorical nature of his orders, remarks and critical statements in relation to his subordinates using a smile and soft, friendly touching, for example:

Stepan Arkadyevitch, without hearing him out, laid his hand genially on the secretary's sleeve. 'No, you do as I told you,' he said, softening his words with a smile, and with a brief explanation of his view of the matter he turned away from the papers, and said... [18].

In the situation of apologizing Oblonsky asks for forgiveness, using repeats in his speech with the intention of emotional impact on the addressee. Furthermore he demonstrates sincere repentance that helps him to achieve certain communication goals, for example:

I am to blame; no words can express how much I am to blame! [18].

Let us give the following examples:

'Dolly, what can I say? One thing: forgive, forgive...; 'Oh, no! Oh, forgive me, forgive me if I have wounded you' [18].

It should be noted that Oblonsky uses in his apologies such phrases as "Forgive!" or "Forgive me!" which are more formal than "I'm sorry". These phrases are typical for the situations when a person asks for forgiveness "for a big fault, for a serious guilt" [22]. Oblonsky shows in the act of apologizing that he takes responsibility for what happened that he has really done something serious. An admission of guilt and repentance allow Stepan Arkadyevitch to achieve the effect of minimizing of damage, which leads to the arrangement of conflicts and renewal of previous interpersonal relations. He knows that all he has to do to achieve success during conversation "is utter the right sentence at the right time" [23].

Manifestations of friendliness which are typical for Oblonsky possess "a tremendous force of illocutionary compulsion" [24] in the acts of communication when it

6. A.Paivio, Mental Representations: A dual coding approach (University of Western Ontario, Canada, 2008)

7. B.Aarts, Conceptions of categorization in the history of linguistics, Language sciences, 28 (4), 361-385 (2006)

8. M.Heidegger, Being and time (State university of New York Press, Albany, 1996) is difficult for his acquaintances, relatives and friends not to show friendly feelings in response. Stepan Arkadyevitch is always greeted with a joyful smile, for example:

'Aha! Stiva! Oblonsky! Here he is!' was almost always said with a smile of delight on meeting him [18].

\section{Conclusions}

Thus, the notion of friendliness is actualized in the Russian linguistic worldview as friendly disposition or friendly attitude of a person in relation to other people. The results of free association experiment let us to distinguish valuable components of friendly attitude such as politeness, sociability, openness, and smile. Friendliness is manifested at the verbal level by a soft intonation, a friendly voice or a friendly tone. At the nonverbal level friendliness is manifested by different facial expressions and gestures. A friendly person, as a rule, smiles, hugs, shakes hands, winks, claps on the shoulder in the Russian-speaking sociocultural environment. Friendliness is associated with a wide variety of positive emotions and feelings that allow the author to classify friendliness to one of the key maxim of behavior in the Russian-speaking community. The most significant manifestations of friendliness for the native speakers are assistance and support.

In this paper the image of a friendly person is presented exemplified by the novel "Anna Karenina". The analysis of verbal and nonverbal samples of communication made it possible to determine vocal expressions, lexical means of language, facial expressions, gestures, actions that are regarded as manifestations of friendliness. Results of this research are significant contribution to the description of the Russian linguistic worldview.

\section{References}

1. Yu.D. Apresyan, Voprosy yazykoznaniya 1, 37-67 (1995)

2. N.D. Arutyunova, Language and the human world (Languages of Russian culture, Moscow, 1999)

3. Ju.M. Malinovich, M.V. Malinovich, Anthropological linguistics. Concepts. Categories (ISLU, Irkutsk, 2003)

4. T.A. van Dijk, Society and discourse: How social contexts influence text and talk (Pompeu Fabra University, Barcelona, 2009)

5. P.Ekman, W.V. Friesen, Journal of Personality and Social Psychology 17, 124-129 (1971)

9. A.A. Zaliznyak, I.B. Levontina, A.D. Shmelev, Key ideas of the Russian linguistic worldview (Languages of Slavic culture, Moscow, 2005)

10. D.N. Ushakov, Explanatory dictionary of the Russian language (Astrel', AST, Moscow, 2000)

11. Big academic dictionary of the Russian language (Science, Moscow, St. Petersburg, 2006) 
12. S.A. Kuznetsov (Ed.), Big explanatory dictionary of the Russian language (Norint, St. Petersburg, 1998)

13. Big encyclopedic dictionary (Ripol, Norint, St. Petersburg, 2006)

14. P.Ya. Chernykh, Historical and etymological dictionary of contemporary Russian language (Russian language, Moscow, 1999)

15. A.G. Preobrazhensky, Etymological dictionary of the Russian language (State Press of foreign and national dictionaries, Moscow, 1959)

16. A.K. Shaposhnikov, Etymological dictionary of contemporary Russian language (Science, Moscow, 2010)

17. Z.Ye. Alexandrova, Dictionary of synonyms of the Russian language (Soviet encyclopedia, Moscow, 1969)
18. L.N. Tolstoy, Anna Karenina, URL: http://www.planetpdf.com/planetpdf/pdfs/free_eboo ks/Anna_Karenina_NT.pdf

19. A.A Potebnya, Thought and language (Sinto, Kiev, 1993)

20. D.S Messinger, A. Fogel, K.L. Dickson, Developmental Psychology 37 (5), 642-653 (2001)

21. E.Otta, E.Abrosio F. Follador, R.L. Hoshino, Perceptual and Motor Skills 82, 1111-1121 (1996)

22. Yu.V. Tufanova, Sociacom, 2 (1), 34-39 (2017)

23. H.H. Clark, E.F. Schaefer, Cognitive science 13, 259-294 (1989)

24. T.S. Ryzhkova, Sociacom 2 (1), 29-33 (2017) 